\title{
A Proposal for Estimating the Order Level for Slow Moving Spare Parts Subject to Obsolescence
}

\author{
Marcello Fera $^{1}$, Alfredo Lambiase ${ }^{2}$, Maria Elena Nenni ${ }^{1}$ \\ ${ }^{1}$ Department of Engineering Management and Economics, Federico II University, Naples, Italy; ${ }^{2}$ Department of Mechanical \\ Engineering, University of Salerno, Salerno, Italy. \\ Email: \{marcello.fera, lambiase, menenni\}@unina.it
}

Received April 18 $8^{\text {th }}, 2010$; revised June 10 $0^{\text {th }}, 2010$; accepted August $1^{\text {st }}, 2010$.

\begin{abstract}
During the last decade technologies have had a significant development in many areas, as military and civil protection, telecommunication and electrical distribution and production. Particularly in the mentioned areas we can find very complex products, with a cycle life generally longer than their components. Companies have thus the need to better manage the replacement of spare parts in order to reduce the holding costs and to satisfy the service level. In this paper authors analyse the state of the art about the spare parts logistic $(S P L)$ problem for products characterized by a long cycle life and by slow moving spare parts subject to obsolescence. A new model to estimate the spare part order level is then proposed and tested on a simulated case.
\end{abstract}

Keywords: Spare Parts Replenishment, Order Level, Obsolescence

\section{Introduction}

Since the late Fifties, the industrial and academic research has concerned in the topic of the spare parts logistic (SPL). During these years many authors have proposed different approaches for analysing and managing the SPL problem, but it remains an open issue. Moreover it has been impossible to individuate a general answer to the problem that is very specialized and depending on the field. In this paper the authors have chosen to focus on the area of military and civil protection, telecommunication and electrical distribution and production. In these fields, companies generally must ensure a very high service level and manage high tech products, as radar or other complex systems, whose components are particularly subject to obsolescence. These features make the SPL problem really critic and strongly linked to other topics as distribution centre localization (DC) [1] and [2] and maintenance management (MM) [3].

So far companies have addressed the problem retaining many spare parts or incurring significant costs of redesigning or finally ignoring it. A structured approach including the obsolescence problem seems to be actually missing. Therefore we propose a new model for spare parts order level estimating as a first step for a new trend on the SPL topic.
Geisler [4], who developed in 1956 a model to plan very efficiently the military supplies, gave one of the first contributions on SPL topic. The model was based on the knowledge of demand, quantity on hand and priority for each item. A second contribution by Wiggins in 1967 [3] is very interesting because he has proposed an inventory control policy aimed to keep in stock maximum one spare part for each item. He was thus focussed to understand exactly when a spare part is needed. The main assumption is that a spare part must be in inventory at time $t^{*}$ resulting from the trade-off between the cost related to the waiting time and the cost related to the holding time.

In 1972 Hausmann [5] proposed a complex formulation of the total cost for spare part management to individuate the optimal inventory policy.

In 1978 some authors [6] introduced the concept of slow moving spare parts, including for them a differentiate cost in a knapsack-type optimization model, which is solvable in exact way only if the total number of parts is under 10.000 .

In 1997 the vision about the SPL topic changed [7]. The problem began to be seen not only related to the inventory, but involving reliability and the whole production management. A model for $n$ parallel machines, located in a production bottleneck and requiring spare parts with a long lead time of supply was developed [8]. The 
authors emphasized the strategic impact of not having spare parts when one of the $n$ machines fails and they included in the cost model parameters from inventory, operations and maintenance management (i.e., holding costs, lead time and downtime cost).

Some authors [9] addressed the SPL problem when the time for waiting spare parts is instead short, including in their model parameters as 1) time, a continuous variable in $[0, \mathrm{~L}]$, where $\mathrm{L}$ is the lifetime of the machine, 2) the lifetime of the part in the machine, exponentially distributed with parameter $\lambda, 3$ ) the purchasing cost, 4) the holding cost and 5) the backorder cost. Particularly they design a model to choose the best policy in function of a factor $R$, which denotes the smallest remaining lifetime for which the stock is increased to 1 , with the assumption it is equal to zero before. The model is aimed to estimating the optimal spare parts order level.

The last two contributions had the meaning to emphasize that delivery time can be a key factor for choosing the optimization model.

In 1999 the SPL problem in the specific case of twoechelon spare parts distribution centre was deeply investigated and linked to the DC topic [1]. Mehrotra et al. [10] used a nonlinear objective function to reduce overall inventory, in case of more than one distribution centre.

In 2000 Strijbosch et al. [11] proposed to use a $\gamma$ distribution for modelling the spare parts' demand.

As a matter of fact, the SPL problem has been investigated for long time and from different points of view. Otherwise many issues are still open just in the field under our focus.

Many problems in the field of military and civil protection, telecommunication and electrical distribution and production are related to a strategic vision of the spare parts management. In fact companies operating on complex systems are increasingly requiring for a maintenance service included in the purchase contract often during the whole cycle-life. For sellers it means planning and optimizing the spare parts management for a horizon of even 35 years. In addition we find the just mentioned criticalities as 1) high service level, 2) slow moving spare parts, 3 ) variable and often very long time for supplying spare parts (delivery time), 4) unknown spare parts' demand, 5) spare parts' obsolescence.

From literature review we have selected the Aka's model as more fitting with our requirements. However it doesn't take in the right considerations points 2) and 4) and it completely lacks of a strategic view. Even the obsolescence problem is addressed just as an item in the holding cost. Regarding the spare parts' demand, the most frequent approach is based on the historical data but in our opinion the link between demand and spare parts' reliability is not thorough enough.

Generally all models solve the SLP problem from a specific point of view, but no one fully embraces our objective.

The proposal is then to set a new specific approach in which the cornerstone and aim of this first paper is the model for estimating the order level.

\section{The Spare Parts Order Level}

The main problem in managing spare parts of complex systems, as radars, satellites, ships, etc., is knowing exactly how many and how long parts have to be maintained in stock. The right answer is linked to the 1) demand rate and to the 2) delivery time for each item.

Regarding 1), it strictly depends on item failure rate. For electric and electronic items, which are the most and more critic in the systems into consideration, the bathtub function is typically as in Figure 1.

As well known, in the first part of the curve the Reliability is described by (1) and the probability density function by (2):

$$
\begin{gathered}
R_{I}(t)=e^{-\left(\frac{t}{\alpha}\right)^{\beta}} \\
f_{I}(t)=-\left(\frac{\beta}{\alpha}\right)\left(\frac{t}{\alpha}\right)^{\beta-1} e^{-\left(\frac{t}{\alpha}\right)^{\beta}}
\end{gathered}
$$

where

$\beta$ is a shape parameter; it is expressed by a pure number, $\alpha$ is the expected life span; it is expressed in days/item, $t$ is the time; it is expressed in days.

In the second part the failure rate is constant. The reliability is thus by (3) and the probability density function by (4):

$$
R_{I I}(t)=e^{-k t}
$$

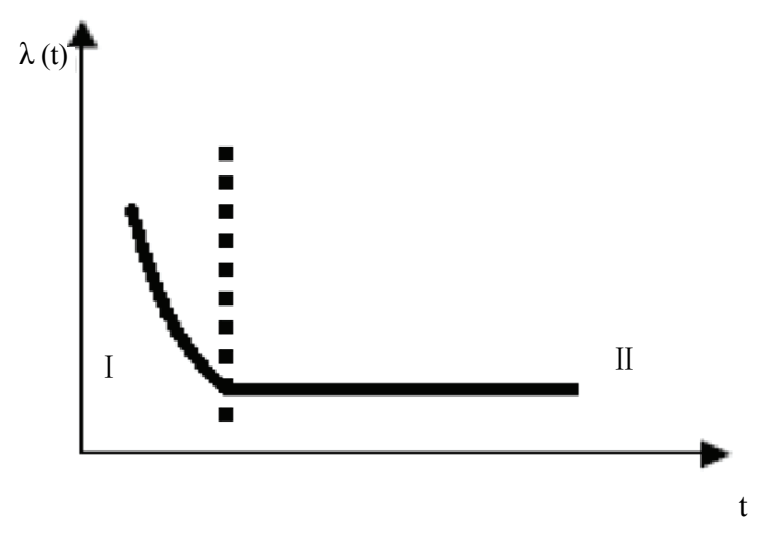

Figure 1. The failure rate (bathtub) function for electric and electronic components. 


$$
f_{I I}(t)=-k \cdot e^{-k t}
$$

where

$k$ is the constant failure rate expressed in items/day,

$t$ is the time, expressed in days.

In both cases the failure rate function is well-known and described respectively by (5) and (6):

$$
\begin{gathered}
\lambda_{I}(t)=-\frac{f_{I}(t)}{R_{I}(t)}=\left(\frac{\beta}{\alpha}\right)\left(\frac{t}{\alpha}\right)^{\beta-1} \\
\lambda_{I I}(t)=-\frac{f_{I I}(t)}{R_{I I}(t)}=k
\end{gathered}
$$

Concerning the delivery time, it is generally calculated through any forecasting model based on historical data. However in case of obsolescence, the delivery time func- tion could have a discontinuity because of changing of item specification or supply condition. The new delivery time should be initially estimated while the forecasting model should be applicable only if new or appropriate historical data are available. Moreover the model will be fitting until obsolescence occurs again. We are now developing a new model based on knowing the approach for the obsolescence managing and on assessing economic and technical parameters, in order to estimate when obsolescence is expected. A first contribution of our study is already reported in Fera, 2008 [12]. In this paper we are limited to use only main result from our studies and we divide the cycle life into parts of length $L(\tau)$, which is the expected time for occurring obsolescence and we consider a delivery time (DT) as a piecewise continuous function in the range $L(\tau)$ :

$$
D T= \begin{cases}D T_{I}=\Theta(L(\tau)) & \text { If the historical data for the item is known } \\ D T_{I I}=\Omega & \text { else }\end{cases}
$$

where

$\Theta(L(\tau))$ calculates the expected delivery time in days and depends on $L(\tau)$;

$\Omega$ is an estimated DT if historical data are unavailable.

According to an order level, order quantity policy ( $r$, $Q)$, the minimum stock level $r$ should be equal to the product between the failure's rate functions and DT. Combining the different functions for the $\lambda$ and $L$, we have four cases: 1) the historical data for delivery time are known and the failure rate is described by a Weibull's function, 2) the historical data for delivery time are known and the failure rate is constant, 3) the historical data for delivery time are unknown and the failure rate is constant, 4) the historical data for delivery time are unknown and the failure rate is described by a Weibull's function.

Minimum stock level for all cases is expressed by $(8,9$, 10,11):

$$
\begin{gathered}
r_{I}=\lambda_{I}(t) \cdot D T_{I}(t)=n \cdot \frac{\beta}{\alpha} \cdot\left(\frac{t}{\alpha}\right)^{\beta-1} \cdot \Theta(L(t)) \\
r_{I I}=\lambda_{I I}(t) \cdot D T_{I}(t)=n \cdot k \cdot \Theta(L(t)) \\
r_{I I I}=\lambda_{I I}(t) \cdot D T_{I I}(t)=n \cdot k \cdot \Omega \\
r_{I V}=\lambda_{I}(t) \cdot D T_{I I}(t)=n \cdot \frac{\beta}{\alpha} \cdot\left(\frac{t}{\alpha}\right)^{\beta-1} \cdot \Omega
\end{gathered}
$$

where:

$n$ is the size of the item.

\section{The Experimental Campaign}

In order to test the effectiveness of our proposal, we have developed the order level and a comparison models both through MATLAB software. By varying the model parameters, as the Table 1 shows, we have derived the experimental plan:

The total life cycle span $(t)$ was fixed in 12500 days about 35 years - and divided into 100 steps. The first part of the bathtub is instead over on the $1000^{\text {th }}$ day. During the whole life cycle span, $r$ should be calculated through models expressed by (8) and (9) both in case of historical data are know (Model I-II) and by (10) and (11) both else (Model III-IV). Models by (8) and (10) are valid until the $1000^{\text {th }}$ day and models by (9) and (11) beyond.

Finally we have summarized results from models in 2 matrixes as in Figure 2 in which $r$ is reported varying parameters during the life cycle span.

In the last row the arithmetic means of the order levels are reported $\left(r_{I-I I}(t)\right.$ and $\left.r_{I I I-I V}(t)\right)$.

Regarding the comparison model we have chosen to use a "conservative approach". We have thus compared results from our proposal with the result from the same model in the worst case, in which parameters assume values to make order level higher. A "conservative approach" is very frequent for several companies in the focused field because it reflects the need to meet the service level agreement.

Table 1. Variation of the order level parameters.

\begin{tabular}{ccc}
\hline Parameter & Range & Step \\
\hline$n$ & $(0,1000]$ & 10 \\
$\beta$ & $(0,2]$ & 0.02 \\
$\alpha$ & $(0,2]$ & 0.02 \\
$L$ & $(0,730]$ & 7.30 \\
$k$ & $(0,2]$ & 0.02 \\
\hline
\end{tabular}



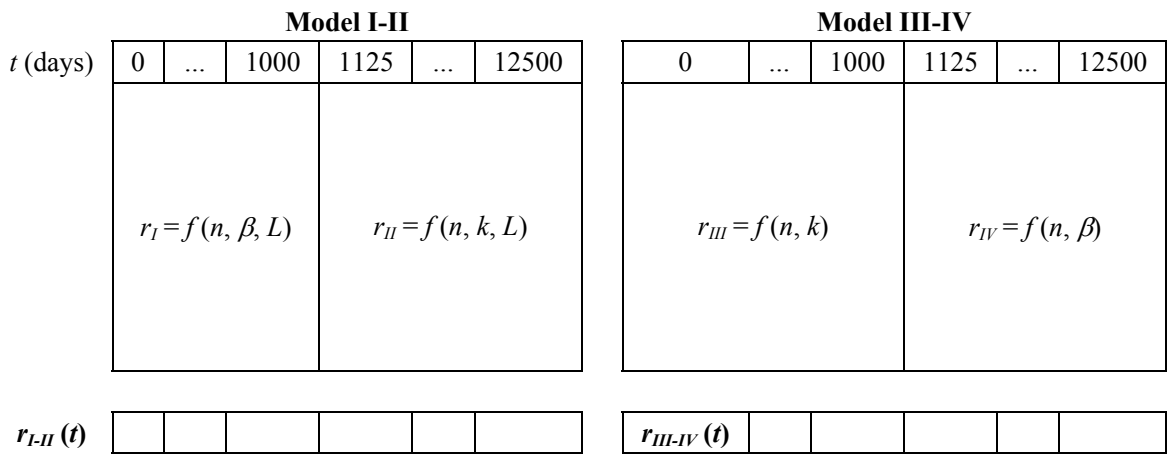

Figure 2. Matrixes in which results from models are summarized.

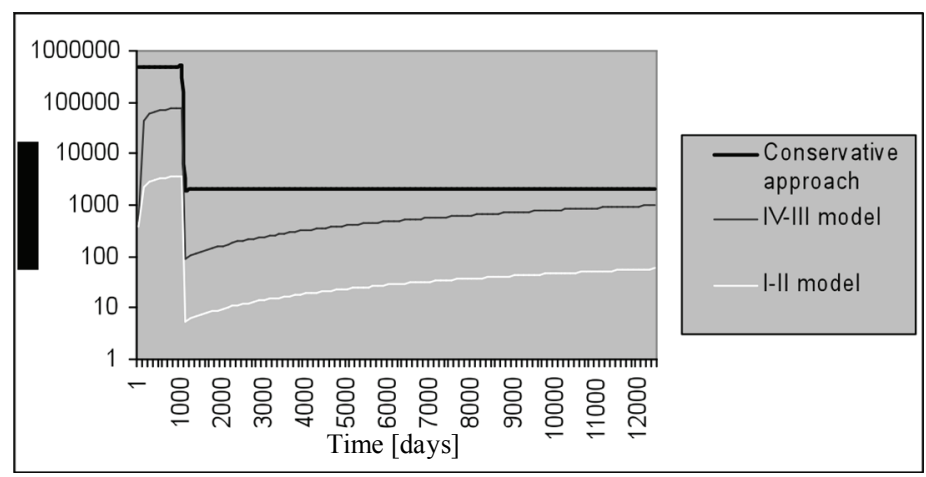

Figure 3. Comparison between the conservative approach and the order level model.

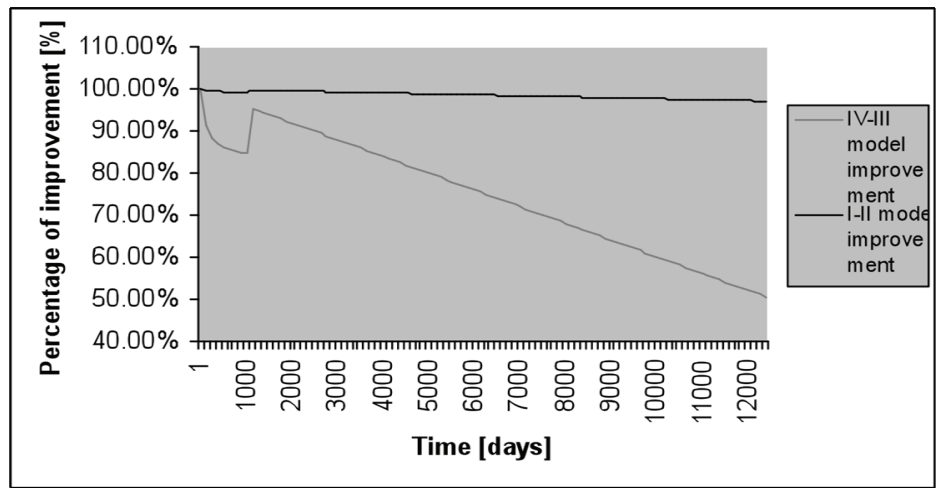

Figure 4. Percentage improvement of the order level model respect to the conservative approach.

In Figures 3, 4, a comparison between the conservative approach and the results from the order level models are reported respectively as size of spare parts and as percentage improvement. Bearing in mind the low effecttiveness of the conservative approach, performance from proposed model looks equally more than acceptable. In fact using Model I-II the percentage improvement is always higher than $90 \%$. In case of Model III-IV the improvement is initially about $90 \%$ but it decreases rapidly during the life cycle span. The phenomenon is explainable considering that unknowing of delivery time is more and more penalizing with the time.

Following the general test, we have investigated three specific cases for which parameters are reported in the Table 2.

Specific cases were chosen because particularly representing of many operative situations in the focused context.

Results from Model I-II and Model III-IV and from the conservative approach are reported partially in the Table 3. From Figures 5, 6 and 7 performance of the proposed model is confirmed. 
Table 2. Parameters for three specific experiments.

\begin{tabular}{cccc}
\hline & Experiment 1 & Experiment 3 & Experiment 3 \\
\hline$\beta$ & 1.5 & 0.6 & 1.05 \\
$\alpha$ & 365 & 100 & 200 \\
$n$ & 500 & 1500 & 1000 \\
$L$ & 120 & 10 & 65 \\
$k$ & $2.7 * \mathrm{E}-03$ & $8.0 * \mathrm{E}-04$ & $1.75 * \mathrm{E}-03$ \\
\hline
\end{tabular}

Table 3. Results from Model I-II and Model III-IV and from the conservative approach.

\begin{tabular}{|c|c|c|c|c|c|c|c|c|c|}
\hline \multirow[b]{2}{*}{ Time } & \multicolumn{3}{|c|}{ Experiment 1} & \multicolumn{3}{|c|}{ Experiment 2} & \multicolumn{3}{|c|}{ Experiment 3} \\
\hline & $\begin{array}{l}\text { Mo. } \\
I-I I\end{array}$ & $\begin{array}{c}\text { Mo. } \\
\text { III-IV }\end{array}$ & Cons. & Mo. I-II & $\begin{array}{c}\text { Mo. } \\
\text { III-IV }\end{array}$ & Cons. & $\begin{array}{c}\text { Mo. } \\
\text { I-II }\end{array}$ & $\begin{array}{c}\text { Mo. } \\
\text { III-IV }\end{array}$ & Cons. \\
\hline 1 & 13 & 16 & 500 & 567 & 1419 & 1500 & 249 & 307 & 1000 \\
\hline 125 & 143 & 180 & 500 & 82 & 205 & 1500 & 317 & 390 & 1000 \\
\hline 250 & 203 & 254 & 500 & 62 & 156 & 1500 & 328 & 404 & 1000 \\
\hline 375 & 249 & 311 & 500 & 53 & 132 & 1500 & 335 & 412 & 1000 \\
\hline 500 & 288 & 359 & 500 & 47 & 118 & 1500 & 340 & 418 & 1000 \\
\hline 625 & 162 & 202 & 500 & 12 & 30 & 1500 & 114 & 140 & 1000 \\
\hline - & . & . & . & . & . & . & . & . & . \\
\hline - & . & . & . & · & . & . & . & . & . \\
\hline • & . & . & . & . & . & . & . & . & . \\
\hline 12500 & 162 & 202 & 500 & 12 & 30 & 1500 & 114 & 140 & 1000 \\
\hline
\end{tabular}

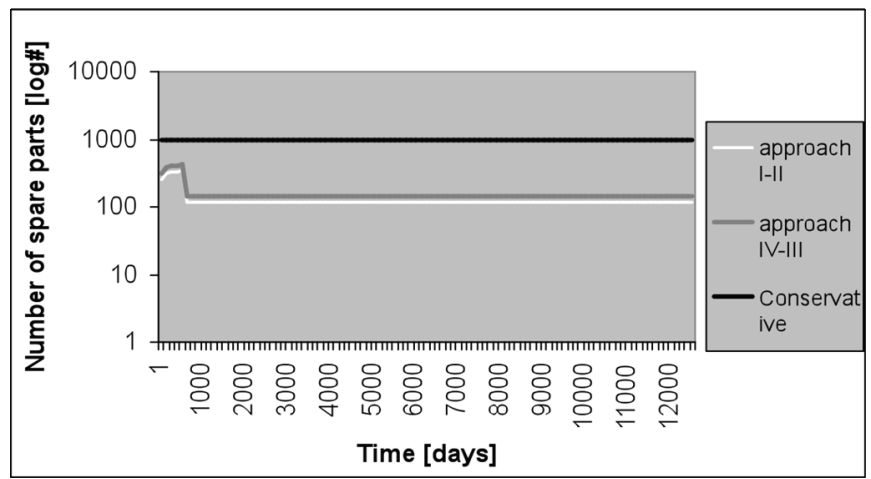

Figure 5. Results from experiment 1.

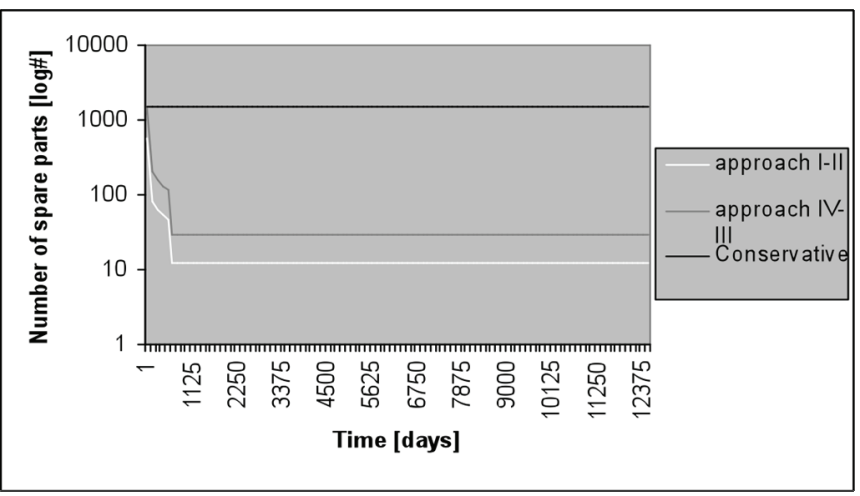

Figure 6. Results from experiment 2. 


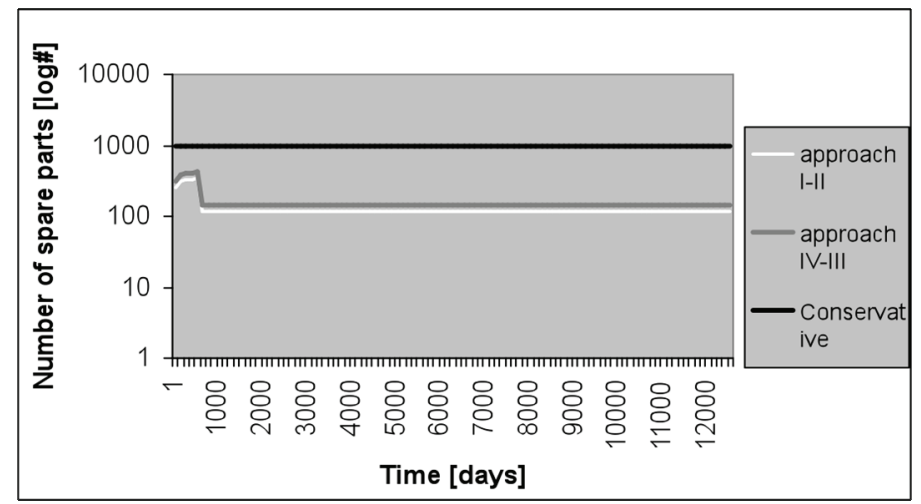

Figure 7. Results from experiment 3.

\section{Conclusions and Open Issues}

In this paper the SPL problem was addressed for slow moving spare parts subject to obsolescence.

Many contributions to the SPL problem have been presented but no one has been recognised as fitting with specific requirements. Authors have thus presented a model for calculating an optimal order level, in which the main idea is of using a delivery time function with a discontinuous trend because of the obsolescence problem.

A first test of effectiveness was conducted comparing the proposal with a conservative approach. The test has demonstrated that the proposed model provides an improvement of about $80-85 \%$ regarding the order level size with the same service level.

Currently the authors are investigating the delivery time function to get a better definition based on the perfect matching between spare parts specifications and approach for the obsolescence problem. But the solution looks already quite good. Next step could be instead focused in introducing the implications of the distribution centre localization on the delivery time.

\section{REFERENCES}

[1] W. J. Hopp, R. Q. Zhang and M. L. Spearman, "An Easily Implementable Hierarchical Heuristic for a TwoEchelon Spare Parts Distribution System," IIE Transactions, Vol. 31, No. 10, 1999, pp. 977-988

[2] P. H. Koo, J. Jang and J. Suh, "Estimation of Part Waiting Time and Fleet Sizing in AGV Systems," International Journal of Flexible Manufacturing Systems, Vol. 16, No. 3, July 2005, pp. 211-228.

[3] A. D. Wiggins, "A Minimum Cost Model of Spare Parts Inventory," Technometrics, Vol. 9, No. 4, November
1967, pp. 661-665.

[4] M. A. Geisler and H. W. Karr, "The Design of the Military Supply Tables for Spare Parts," Operations Research, Vol. 4, No. 4, August 1956, pp. 431-442.

[5] W. H. Hausman and L. J. Thomas, "Inventory Control with a Probabilistic Demand and Periodic Withdrawals," Management Science, Vol. 18, No. 5, January 1972, pp. 265-275.

[6] L. F. Gelders and P. M. Van Looy, "An Inventory Policy for Slow and Fast Movers in a Petrol-Chemical Plant: A Case Study," Journal of the Operation Research Society, Vol. 29, No. 9, September 1978, pp. 867-874.

[7] H. Block and H. Joe, "Tail Behaviour of the Failure Rate Functions of Mixtures," Life Time Data Analysis, Vol. 3, No. 3, 1997, pp. 269-288.

[8] M. Aka, S. M. Gilbert and P. Ritchken, "Joint Inventory/ Replacement Policies for Parallel Machines," IIE Transactions, Vol. 29, No. 6, 1997, pp. 441-449.

[9] W. K. Haneveld and R. H. Teunter, "Optimal Provisioning Strategies for Slow Moving Spare Parts with Small Lead Times," Journal of the Operational Research Society, Vol. 48, No. 2, February 1997, pp. 184-194.

[10] A. Mehrotra, N. R. Natraj and M. A. Trick, "Consolidating Maintenance Spares," Computational Optimization and Applications, Vol. 18, No. 3, March 2001, pp. 251271.

[11] L. W. G. Strijbosch, R. J. M. Heuts and E. H. M. van der Schoot, "A Combined Forecast Inventory Control Procedure for Spare Parts," Journal of the Operational Research Society, Vol. 51, No. 10, October 2000, pp. 1184 1192.

[12] M. Fera, "Sviluppo di un Modello di Supporto a Decisione per la Gestione dell'Obsolescenza per Ricambi con alti Lead Times di Produzione e Appartenenti a Sistemi con Lunghi Cicli di Vita," Ph.D. Dissertation, Federico II University, Naples, 2008. 